\title{
La autonomia de la migración: Una perspectiva alternativa sobre la movilidad humana y los controles migratorios ${ }^{1}$
}

\author{
Autonomy of migration: An alternative perspective on human \\ mobility and migration control
}

\author{
Maribel Casas-Cortés, PhD \\ Investigadora Ramón y Cajal \\ Universidad de Zaragozas \\ drcasascortes@unizar.es (ESPAÑA)
}

Sebastian Cobarrubias, PhD

Investigador ARAID

Universidad de Zaragozas

scobarru@araid.es (ESPAÑA)

Recibido: 08.01 2019
Aceptado: 04.02.2019

\section{RESUMEN}

Las migraciones y los controles migratorios se han convertido en objeto de máximo interés académico, institucional y mediático. Además de los enfoques convencionales sobre la movilidad humana y su gestión, han surgido interpretaciones alternativas con repercusiones epistemológicas, metodológicas y políticas. Este artículo se centra en la emergencia de la escuela de pensamiento llamada "la Autonomía de la Migración". A través del análisis de las obras de varios autores y proyectos (algunos cartográficos), que se han ido consolidando como referen-

${ }^{1}$ Este artículo se realiza bajo la financiación del Subprograma Ramón y Cajal del Fondo Social Europeo y la Agencia Estatal de Investigación de España (RYC2018-024990-I), y de ARAID (Fundación Agencia Aragonesa para la Investigación y el Desarrollo). Este artículo constituye una recopilación de los puntos clave de una teoría en alza entre los círculos académicos que hemos frecuentado en nuestros últimos años de investigación. Agradecemos la inspiración a referentes de esta escuela de pensamiento como Nicholas De Genova, Sabine Hess, Sandro Mezzadra, y Martina Tazzioli entre otros. También agradecemos el interés en esta teoría y la posterior invitación de Ana María López Sala para participar en este monográfico de Empiria.. 
tes de esta tradición política, teórica y metodológica, identificamos una serie de conceptos clave y realizamos una genealogía de dicha escuela de pensamiento, dando a conocer los múltiples contextos donde surge y se difunde entre varias disciplinas e iniciativas activistas, incluyendo algunas de las reacciones críticas a sus posibles limitaciones. Abordamos algunas de sus consecuencias metodológicas a través de un ejemplo empírico.

\title{
PALABRAS CLAVE
}

Autonomía, estudios migratorios, fronteras, autonomía de la migración, movimientos sociales, teoría social crítica.

\begin{abstract}
Migration movements and migratory controls are becoming a hot topic within academia, governmental institutions and media circles. Beyond conventional approaches to human mobility and its management, alternative interpretations are surfacing with important epistemological, methodological and political repercussions. This piece focuses on the emergent school of thought known as "Autonomy of Migration". By engaging the textual production and projects (including cartographies) of key authors and collectives of this tradition, we identify central concepts of this political, theoretical and methodological school of thought. We also trace a genealogy of this tradition, pointing to the different historical contexts from which it emerged and expanded to several scholarly fields and activist initiatives, including some of the critical reactions to its possible limitations. This article includes a brief discussion on its methodological underpinnings through an empirical case.
\end{abstract}

\section{KEY WORDS}

Autonomy, migration studies, borders, autonomy of migration, social movements, critical social theory.

\section{INTRODUCCIÓN}

Este artículo se plantea como una introducción a una teoría en alza dentro de los estudios de fronteras y migraciones internacionales con repercusión en planteamientos epistemológicos, metodológicos y políticos. La Autonomía de la Migración surge como una respuesta a los enfoques convencionales de entender las migraciones, la regulación de la mano de obra migrante, las fronteras, así como las nociones de ciudadanía en contextos globalizados. Esta perspectiva 
surge en unos contextos históricos concretos, principalmente en los años noventa en el centro y sur de Europa, siendo resultado de una imbricación mutua entre activismo político cuestionando la eficacia y consecuencias del sistema fronterizo en curso por un lado, y por otro, ciertos replanteamientos teóricos sobre la movilidad humana. El trabajo de varios autores, grupos de investigación y colectivos coinciden en un esfuerzo de ir más allá de los paradigmas comúnmente aceptados dentro del campo de los estudios de las migraciones, tales como las interpretaciones estructurales, los análisis basados en decisiones racionales por parte de individuos y hogares, los enmarcados en nacionalismo metodológico, o los que utilizan conceptos de agencia y empoderamiento. El intento del presente artículo es introducir esta tendencia teórica, metodológica y política con repercusión en los estudios migratorios de otros contextos linguísticos y geográficos, como contribución a esta edición especial de Empiria: Revista de Metodología de Ciencias Sociales.

La escuela de pensamiento denominada Autonomía de la Migración (AdM) inicialmente intenta responder a las limitaciones percibidas en dos tendencias presentes en los estudios migratorios clásicos, tradicionales o canónicos. Por un lado, las teorías neoclásicas que veían la elección de migrar como una decisión racional de maximización de costes y beneficios percibidos por parte de individuos, hogares o grupos pequeños. Por otro lado, las explicaciones estructurales (como la teoría del sistema-mundo o del mercado laboral dual) donde la libre elección del migrante está circunscrita por limitaciones que condicionan decisiones cuasi-involuntarias. Incluso teorías más recientes de las migraciones que matizan la dicotomía entre estructura y elección como: redes/cadenas de migración, instituciones de facilitación, sistemas migratorios o causación colectiva, aunque compaginables en varios puntos con la teoría de la AdM, no llegan al mismo nivel de replanteamiento teórico avanzado por los autores de la AdM.

Una aportación importante de la AdM consiste en interpretar el desarrollo de las regulaciones migratorias y las políticas fronterizas como dinámicas en cambio constante, que interactúan con las migraciones pero que no las afectan de manera causa - efecto en forma aritmética (ej. más control, menos migración). Además la AdM se frustra con el nacionalismo metodológico por limitar el punto de partida de los análisis migratorios en casos concretos. Para los teóricos de la AdM, la migración no es una anomalía que hay que explicar, o el resultado mecánico de desequilibrios de oferta y demanda en los mercados laborales. Por lo tanto, dos preguntas fundamentales de los estudios migratorios clásicos, se desvanecen: “¿por qué la gente migra? ¿por qué continúa migrando?”.

El propósito de la AdM no consiste en limitar, ni gestionar, ni integrar a los migrantes. Con lo cual las implicaciones políticas de la AdM distan de algunas interpretaciones de los estudios migratorios, donde se asume "la perspectiva de gobierno" en el sentido amplio. Algunos proponentes de la AdM, critican a los estudios migratorios por asumir el "punto de vista del nativo" (De Genova 2005), un nativo además en abstracto que entiende la migración como fenómeno anormal y preocupante en sí mismo. De hecho, varios autores de la AdM argumentan que los estudios migratorios tienen su origen en los intentos de 
incorporar e integrar a inmigrantes en programas de industrialización y crecimiento económico en general (Mezzadra 2011; Casas-Cortés et al. 2014). Estas teorías pueden parecer hoy estáticas cuando se tiene en cuenta las experiencias heterogéneas de la migración, y la "turbulencia" de las migraciones vistas como fenómeno global y continuo (Papastergiadis 2000). La AdM plantea, ¿qué pasa si interpretamos las migraciones como motor de cambio? ¿Qué ocurre si los análisis se realizan desde el punto de vista de las migraciones y la movilidad misma en vez de adoptar una mirada estatal?

Uno de los autores claves en iniciar y desarrollar la teoría de la AdM es el economista e historiador económico Yann Moulier-Boutang. Boutang, junto con su co-autor Garson, se atrevieron a plantear, después de varios estudios, que las migraciones no siguen de manera estricta u predecible las dinámicas clásicas de mercado laboral, ni de oferta y demanda, ni de reserva de mano de obra (Moulier-Boutang and Garson 1984). Las teorías que subyacen a este tipo de explicaciones de la migración laboral no corresponden a las complejidades empíricas. Basados en evidencia histórica, concluyeron que las migraciones actúan con "cierta autonomía" de las causas (tanto estructurales, como de racionalidad económica). Inspirados en la potencialidad de pensar la migración con cierta autonomía, un colectivo de activistas/artistas/investigadores basado en Alemania lo dice de manera mas irónica en su texto "Speaking of Autonomy of Migration: Racism and Struggles of Migration" (2004):

"Nadie estaría de acuerdo con que la migración transcurre en total paz y libertad. Nadie imagina a un inmigrante calculando el nivel de eficiencia del mercado internacional de trabajo por la mañana, por la tarde escogiendo un país a donde inmigrar, y desde entonces disfrutando los frutos de su movilidad". (Kanak-Attack 2004) ${ }^{2}$

Este artículo realiza una síntesis de la escuela de pensamiento constituida como la Autonomía de la Migración. La primera parte introduce la noción de autonomía y la comprensión de la migración como movimiento social a través de las obras de varios autores y proyectos que se han ido consolidando como referentes de esta tradición política, teórica y metodológica. La segunda parte realiza una genealogía de dicha escuela de pensamiento, dando a conocer los múltiples contextos donde la AdM surge y se difunde entre varias disciplinas e iniciativas activistas. La tercera parte aborda los conceptos claves y recurrentes entre los teóricos de la AdM, así como algunas de las críticas incipientes a dichos conceptos. Esa sección es seguida por un breve ejemplo de estudio empírico bajo el marco teórico de la AdM. La conclusión, "bailando sin fronteras", parte de expresiones musicales recientes que reflejan como la manera de pensar de la AdM se está difundiendo por medios académicos, artísticos, organizativos y también musicales. Dichas expresiones contra-culturales frente a la normalización del Estado-nación, la ciudadanía y las fronteras, coinciden con esta corriente de pensamiento que aboga de múltiples formas, por eliminar las fronteras como

2 Accesible en http://www.kanak-attak.de/ka/text/esf04.html ) 
instrumento político-legal y apoyar las prácticas de libertad de movimiento como una política no-utópica, sino ejercida y encarnada de facto a través de muchas personas on the move.

\section{LA MIRADA AUTÓNOMA: REPRESENTACIONES ALTERNATIVAS DE LAS MIGRACIONES}

"Si no hubiera fronteras, no se llamaría migración"

Nicholas DeGenova

Empezamos hablando de cómo se entiende la autonomía en esta teoría a través de MigMap. MigMap fue un proyecto artístico alemán realizado en el contexto de un programa más amplio, Transit Migration, que se desarrolló entre 2002 y 2006. Este programa fue una investigación sobre cómo los movimientos migratorios han ido transformando la política y el discurso sobre el gobierno, la ciudadanía y las relaciones laborales. Un proyecto interdisciplinar inspirado en la AdM y que denuncia los regímenes de frontera desde una "mirada autónoma", integrando colaboraciones provenientes del mundo de la universidad, del cine, del arte en general y de los movimientos sociales.

\section{Figura 1. Map2 on Discourses by Transit Migration Research Project "MigMap"}

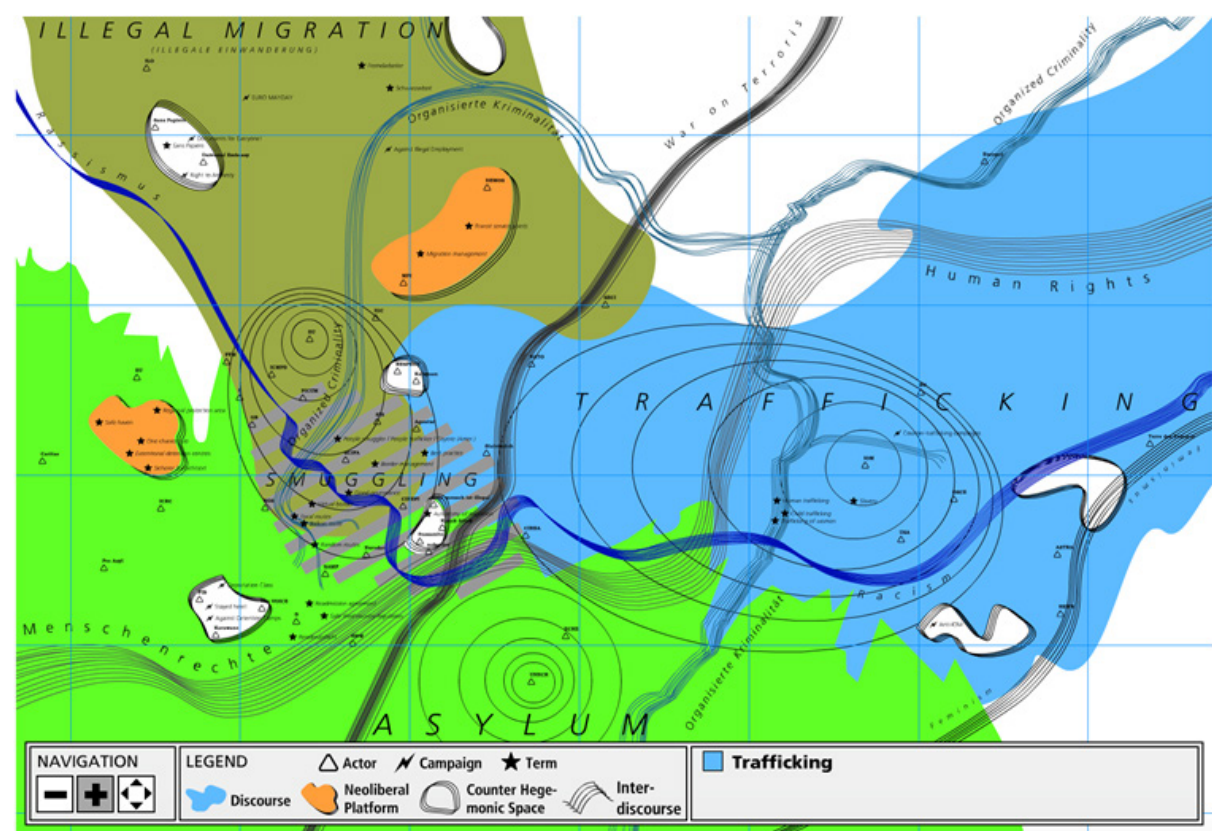


MigMap intenta mostrar en cuatro mapas interactivos, en inglés o en alemán, cómo y dónde se está produciendo el conocimiento en el área de las migraciones y cómo están funcionando las nuevas formas de gobierno supranacional que se observan en el régimen migratorio europeo. Los cuatro mapas se denominan "Key Players", "Discourses", "Europeanisation" y "Places + Practices", y permiten acceder, a modo de diccionario gráfico, a una ingente cantidad de información sobre agentes sociales, debates, procesos y acontecimientos relacionados con las políticas migratorias. Reflexionando sobre este proyecto de investigación y militancia, Manuela Bojadžijev y Serhat Karakayali proponen que estas maneras de observar, analizar y cartografiar llevan hacia una "metodología" diferente $(2007 ; 2010)$. Explican cómo esta investigación buscaba entender qué es lo que la inmigración nos enseña sobre las condiciones sociológicas contemporáneas, y otros aspectos que van más allá de las políticas de gestión migratoria. También formando parte de este proyecto, Marion Von Osten, enfatiza la importancia de la reflexividad para preguntarse: "cómo re-presentar este 'objeto' de estudio," (2016: 1). Ella propone la Autonomía de la Migración como forma alternativa de representar, y por tanto, concebir la migración que no asume ni el Estado-nación, ni la Europa Fortaleza, ambas con sus feroces fronteras, como realidades asumidas e incuestionables. La serie de mapas de MigMap muestra de forma gráfica lo que el teórico Sandro Mezzadra llama "la mirada autónoma", la cual conlleva cambios radicales de perspectiva a la hora de analizar las migraciones. Primero, que la migración no es solo una "reacción" a fuerzas estructurales, y segundo, que tampoco es una decisión individual en el vacío. La movilidad humana se concibe como una fuerza creativa que interactúa con estas estructuras y por lo tanto, es más que un cúmulo de decisiones individuales. Las prácticas, demandas y deseos migrantes superan a los criterios 'objetivos' o 'sociológicos' que tratan de explicar los flujos de movilidad humana. Este 'exceso' significa que la migración no puede reducirse a 'leyes' de oferta y demanda o políticas estatales (Mezzadra 2011: 126).

Según Mezzadra, estas prácticas autónomas de la migración han causado una auténtica crisis de flujos gobernables porque la migración no corresponde a las metáforas hidráulicas que se suelen utilizar para describirlas. No se puede parar el flujo de la migración del mismo modo que se cierra un grifo insiste el autor. En este sentido, la migración se entiende como parte de una constelación de mayor escala, formada por una serie de relaciones sociales y de procesos de conflicto, no simplemente como una respuesta a la variable de pobreza o una consecuencia de las redes de coyotes y contrabando. Y aquí cabe explicar un poco más sobre cómo se entiende el concepto de autonomía:

"La AdM no ignora la relevancia de las estructuras sociales, legales, políticas, culturales y económica a la hora de pensar las migraciones. Al contrario, su punto de partida no son los inmigrantes individuales, sino el movimiento migratorio como un proceso social y como una fuerza creativa dentro de estas estructuras". (Entrevista a Mezzadra 2011:587) 
En este sentido la AdM asume el giro Foucaultiano de no entender al poder como totalizante y represivo. El concepto de autonomía se basa en una distribución compleja de los recursos y agentes de control, en este caso, como parte de los circuitos de la migración. De esta manera, en vez de enfocarse en los sistemas de control fronterizo, la autonomía tiene otro punto de partida:

"La Autonomía parte de los esfuerzos de los inmigrantes, de su habilidad para moverse, de su deseo de ir más allá de espacios confinados, tribales, nacionales..." (Heidenreich and Vukadinovc 2008: 141)

Desde la teoría crítica, sobre todo inspirada en el pensamiento de Foucault y Deleuze, algunos teóricos de la autonomía conciben "la movilidad transnacional como una fuerza irreductible" que va más allá, pero también a su vez, es dependiente de las causas que llevan a las personas a emigrar o huir (Papadopoulos, Stephenson, and Tsianos 2008). Del mismo modo, esta "fuerza irreductible" es capaz de sobreponerse a la rigidez de los controles migratorios, como reza uno de los eslóganes de los Sans Papiers "estamos aquí, porque hemos cruzado vuestras fronteras". Estas victorias cotidianas no niegan que muchos de los procesos de movilidad internacional sean dolorosos. Todo lo contrario, la AdM denuncia de forma habitual las consecuencias de los sistemas fronterizos como productoras de catástrofes humanas evitables: creciente número de muertos, heridos, desplazados forzosos, familias separadas, etc.

Como consecuencia de asumir la migración como proceso constante y parcialmente independiente de otros factores, la AdM observa una dinámica histórica clave que consiste en querer controlar la movilidad, y cuando esto sucede, otras movilidades surgen en respuesta a estos esfuerzos de gestión: "Las luchas sobre la movilidad atraviesan toda la historia del capitalismo." Esta afirmación lleva a decir que "no hay capitalismo sin control de la movilidad," (Mezzadra 2011: 124). ${ }^{3}$ Por una parte, el Estado y el capital tratan de gestionar la movilidad, reducir su exceso, y reapropiarlo dentro de sus códigos. Por otro lado, las luchas de los inmigrantes emergen en contra de estos dispositivos, llevando a movilidades que exceden ese régimen migratorio. Entonces es vital poner atención a estas dinámicas; muchas de las cuales ocurren en el ámbito de lo cotidiano, incluyendo las prácticas de supervivencia sin expresiones públicas. Solo así, es posible entender con mayor profundidad las formas y mutaciones de los regímenes actuales de ciudadanía, sistemas fronterizos y configuraciones de contratación laborales.

La movilidad humana cobra así una centralidad analítica inusitada, como factor explicativo de numerosas transformaciones a nivel socio-político y económico. La AdM también contribuye a entender como la migración y la movilidad

${ }^{3}$ Para algunos autores claves de la AdM, como Boutang y Mezzadra, la conexión entre la historia del capitalismo y la historia del control de la movilidad humana es clave, en parte por la conexión entre la conceptualización de la "autonomía" de la AdM con la Autonomía del marxismo heterodoxo. Esto no implica que los diferentes autores trabajando con el marco de la AdM afirman que el control de la movilidad humana (o su intento) coincide con los inicios del capitalismo. El intento parece ser entender la movilidad humana como clave en la historia económica moderna, y no simplemente un "efecto" del desarrollo de esa misma economía. 
internacional afectan al régimen legal y político de gestión de las poblaciones, tanto a las políticas fronterizas (por ejemplo: las deportaciones, los procesos de externalización de fronteras), como también al desarrollo de los contratos laborales. Este último punto se basa en el trabajo de Boutang, quien analiza el desarrollo del derecho laboral y la evolución de tipos de contratos como ejemplos históricos del intento de controlar la movilidad de ciertas poblaciones. Boutang, con su rastreo históricos, muestra como:

"Cada vez que se embrida el mercado laboral, esto es, cada vez que la movilidad del trabajador dependiente se ve de una u otra manera limitada, se desarrolla, como respuesta a la aparición de nuevos canales de fuga, una extensión de la transacción dinero/trabajo a la esfera de la vida cívica y política. La limitación del acceso a la ciudadanía, a la ciudad, a la vivienda, a la exogamia, está estrechamente ligada al control de la fuga de los trabajadores dependientes". (Moulier-Boutang 1998/2006: 37)

Es así como se llega a formular el cuasi-eslogan de "la migración como movimiento social" recogido por varios escritos de maneras diferentes, y también inspirando a colectivos trabajando por la libertad de movimiento:

"Esta cualidad del "exceso" lleva a un enfoque que concibe la migración como un tipo único de acción colectiva, retando poderes institucionales para reformular el régimen fronterizo". (Mezzadra 2011: 129)

Para otra teórica de la AdM, Angela Mitropulus, el concepto de autonomía es una manera de pensar la migración "como un acto político en sí mismo" (Mitropoulos 2011). Esta re-significación de la migración como "fuerza creativa" y "exceso" evita la noción liberal de la acción política como voluntad individual y afirma el carácter impredecible y ambivalente de la movilidad humana. Este surplus, exceso y fuerza creativa se entiende hasta tal punto que muchos adscritos a la AdM consideran la migración como un "movimiento social", pero no estrictamente con sus connotaciones de activismo y representación política en una esfera pública:

"Hablar de la "autonomía de la migración" significa entenderlo como un movimiento social en el sentido literal de las palabras, y no como una mera respuesta a malestares económicos y sociales". (Mezzadra 2011: 587)

Muchas iniciativas críticas con la política fronteriza de la Unión Europea han adoptado esta proposición de entender la migración como un movimiento social en sí (Frassanito Network, NoBorders Network, algunas campañas anti-deportaciones, etc.). Según estos colectivos, esta perspectiva permite alianzas más horizontales entre los que 'están' y los que 'llegan', además de poder terminar con paradigmas de asistencialismo y paternalismo en acciones de solidaridad en temas de migración. Sin embargo, justamente un enfoque en acciones con carácter público, con representación aunque no sea electoral, limitaría lo que es la potencia política de la AdM. Esta teoría insiste en que las luchas de los migrantes no se limitan a procesos explícitos de movilización social, con carácter público, representantes, demandas concretas y tácticas colectivas. Por lo contrario, pro- 
pone la inmigración como movimiento social refiriéndose a todo el proceso amplio de movilidades, redes, deseos, superación de retos y límites que implica la movilidad humana en colectivo pero más allá de un grupo, plataforma o un ciclo de movilizaciones. La AdM también utiliza el concepto de "movimiento social" para referirse a las luchas organizadas y explícitamente políticas por el reconocimiento de población extranjera, el acceso a derechos sociales, el cumplimiento de una política "sin fronteras", etc. Pero además, movimiento social también abarca a los procesos de movilidad internacional en curso. Para la AdM, el hecho en sí de traspasar fronteras a pesar de legislaciones restrictivas que no cumplen con el "Right to Move" o 'Ius Migrandi' (el derecho a migrar explorado por el jurista aragonés Chueca-Sancho 2010; Fernández Sola 2018), constituye un acto colectivo con potencia teórica y política que merece la pena indagar. En términos de investigación, la teoría de la autonomía de la migración contribuye a un estudio más amplio de los procesos de movilización explícita por parte de colectivos inmigrantes, dado que rechaza interpretaciones percibidas como paternalistas o victimizantes, o las que aislan las luchas migrantes a demandas sectoriales de un grupo concreto. Al contrario, AdM parte desde una comprensión que sitúa esas luchas sociales como parte de una transformación social más amplia en proceso incluyendo: la movilización explícita, la movilidad humana en sí y su organización, y la supervivencia cotidiana de personas a pesar de legislaciones restrictivas de extranjería. Una transformación que es justamente la desestabilización del régimen estático de los Estados-nación. Las luchas de inmigrantes cobran así relevancia epistemológica y política (Tazzioli 2015: 80-83).

Esta interpretación fue bien acogida en estudios de movimientos sociales, y por lo tanto, la presencia de la teoría de la autonomía de las migraciones es más notable en este campo que en otros, especialmente en referencia a los movimientos por los derechos de los migrantes. Es importante notar también que la autonomía de la migración surge como un encuentro entre el desarrollo teórico del concepto post-marxista de la autonomía y las luchas sociales contemporáneas de inmigrantes. Con ejemplos como los autores Manuela Bojadžijev y Serhat Karakayali en Alemania, Sandro Mezzadra en Italia, Yann Moulier Boutang en Francia, Petit en España, tenemos ejemplos de intelectuales de la autonomía alemana, italiana, francesa y española que entrelazan sus investigaciones con una implicación personal en las luchas de inmigrantes en sus países, en este sentido contestando al planteamiento de Balibar: “¿qué debemos a los sin papeles?" (Balibar 2009). Estos ejemplos muestran como la autonomía de la migración surge como una manera de interpretar los movimientos migratorios desde el punto de vista de los inmigrantes en procesos antagonistas.

Además, muchos de los participantes en los colectivos pro-migrantes y antifronteras están conectados con la tradición teórica-política del Marxismo Autónomo (también conocido como el Operaismo Italiano). Desde esta perspectiva, militantes del marxismo autónomo, se acercan a estas luchas de inmigrantes de una manera diferente a la convencional. Por ejemplo, veremos cómo es un acercamiento que va más allá de la caridad y la solidaridad vertical hacia supuestas víctimas; más allá de un marco teórico que encuadra la migración como un pro- 
blema entre exclusión versus inclusión social; y más allá de una celebración de la voluntad política del inmigrante (immigrant agency como tema implícitamente asumido en muchos casos dentro de los Estudio Diaspóricos, el transnacionalismo, y los Estudios Culturales).

\section{GENEALOGÍA DE LA TEORÍA AUTÓNOMA DE LAS MIGRACIONES}

Figura 2. Grafiti callejero con la imagen del icono cinematográfico Oso Paddington, bajo el slogan "la migración no es un crimen," April 2009 Lünen, Germany, Foto: mkorsakov. Flickr (CC BY-NC-SA 2.0)

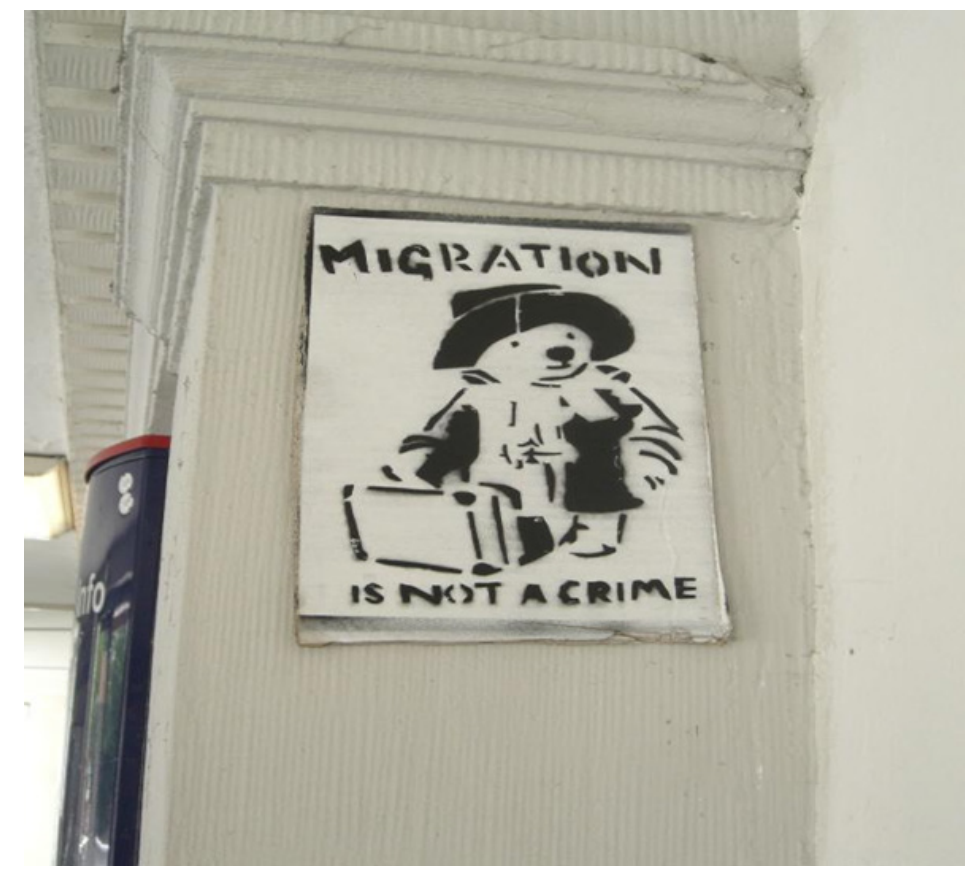

Como punto de inflexión en esta presentación, analizamos el contexto histórico donde se planteó la interpretación de la migración con la lente de la autonomía. La autonomía de las migraciones constituye un cambio analítico innovador para conceptualizar la relación entra las vidas en movimiento y las prácticas de gestión migratoria. Es decir, la Autonomía de la Migración representa un giro relevante en los estudios migratorios clásicos descentrando el enfoque convencional: en vez de concentrarse en las "razones que explican las migraciones" o en "los controles migratorios" per se, el punto de interés se centra en la compleja 
relación entre las diversas movilidades humanas y los regímenes de poder en marcha.

"Se diseñó para liberar la investigación y activismo ligado a la migración de algunos de los marcos dominantes (ej. Humanitarismo, securitarización, gestión de las migraciones, mercado laboral, etc.)". (Nyers 2015: 26).

La mirada autónoma presta atención a cómo las migraciones responden a las prácticas de control fronterizo, pero también a cómo operan de manera independiente a ellas, y al mismo tiempo a cómo influyen en dichas instituciones y sus políticas de gestión de poblaciones. Esta lectura surgió en el contexto de los primeros esfuerzos organizativos por parte de migrantes indocumentados en Francia lidiando con las consecuencias de políticas migratorias cada vez más restrictivas que se tomaron tanto a nivel estatal como a nivel de la Comunidad Europea desde finales de los 80. Las iniciativas colectivas de aquel momento reuniones, acciones públicas, huelgas de hambre, etc.- desarrolladas sobre todo en centros urbanos franceses, coincidieron con el movimiento de los parados que sacó a la luz la problemática del desempleo estructural en Europa. Fue en esta época cuando se empezó a politizar de manera más mayoritaria la cuestión de la vulnerabilidad laboral, pero también, migratoria, bajo el término "precariedad".

\section{- Primeras movilizaciones de los Sans-Papiers en Francia}

Yann Moulier-Boutang, quien estaba trabajando con los esfuerzos "híperminoritarios" de los Sans-Papiers por veinticinco años ya en los noventa, señaló la especificidad laboral y subjetiva de la figura del 'sin-papeles':

"En el caso del extranjero estamos, en efecto, ante un trabajador asalariado y, sin embargo, ¿quién sería capaz de sostener que es tan libre como un trabajador asalariado ordinario?" (Moulier-Boutang 1998/2006: 31)

Desarrolló una serie de escritos novedosos sobre la cuestión de la movilidad, defendiendo revertir las lógicas dominantes, establecidas desde las políticas estatales trabajando, para la integración y la coherencia institucional (Moulier-Boutang 1998). Según Boutang, la migración había sido atribuida desde hacía mucho tiempo a un razonamiento limitado a lógicas económicas de oferta/demanda del mercado de trabajo, y tratadas como una cuestión de regulación administrativa. Para Boutang, la primacía de la movilidad en la historia del capitalismo es lo que él define como "autonomía de la migración". Realizando una lectura marxista heterodoxa de la economía-mundo, propone las luchas de los esclavos como uno de los principales motores para la llegada del trabajo asalariado libre. En esta genealogía de la movilidad revierte la relación convencional entre la administración estatal y la movilidad, señalando cómo los llamados expertos y agencias de 
gestión migratoria han fallado en reconocer la fuerza y los efectos de los flujos migratorios. ${ }^{4}$

Los trabajos de Boutang se diseminaron a través de revistas políticas como Multitudes (entre otros). De esta manera sus análisis coincidieron, inspiraron y cooperaron con muchas iniciativas de movilización social sobre temas relacionados con la precariedad en Francia y que tuvieron resonancia en otros países europeos: la lucha de los Sans-Papiers, grupos como Agir contra la Precarieté, las Asambleas de Desempleados, y otros movimientos.

\section{- Activismo anti-racista en Alemania}

La lectura de Boutang, enfatizando una visión alternativa y central de la movilidad, resonó con el trabajo realizado por círculos activistas centrados en el tema del racismo en Alemania. Durante las décadas de los 1990 y 2000, un grupo de "migrantes de segunda generación" (así llamados) asumieron la perspectiva de la AdM como metodología de análisis y acción política, emprendiendo iniciativas de investigación y movilización. ${ }^{5}$

En 2010, reflexionando sobre esos cambios en perspectiva afectando el trabajo activista y académico, Manuela Bojadžijev and Serhat Karakayal apuntaron:

"Hace 10 años, dimos un nombre a nuestros esfuerzos por crear una nueva base para el trabajo político con la migración: "la autonomía de la migración". Término deslumbrante, eslogan, y programa, todo esto a la vez, su uso principalmente funcionó para muchos como un acto de liberación. [ ] Exigía que se dejara a los migrantes hablar de sus luchas, y sobre todo ofreció a la migración descubrir su propio lenguaje [...] fuera del victimismo". (Bojadžijev and Karakayali 2010: 1)

Esta lectura también enfatiza las diferentes capas de singularidad dentro de la etiqueta de migrante (hombre o mujer, trabajador o empresario, ciudadanos, con visado o sin papeles, entre otros). Intervenir en apoyo de esta diversidad se volvió una prioridad en muchas movilizaciones políticas, sobre todo por la red de activistas anti-racistas, Kanak-Attack. El término de "Kanak" en Alemania normalmente se refiere a los habitantes de la ex-colonia alemana de Nueva Guinea, y se había convertido en un insulto racista usado en contra de trabajadores con visado de trabajo limitado. El número de "guest-workers" se multiplicó en

${ }^{4}$ Los trabajos de Yann Moulier-Boutang han sido una referencia para el activismo promigración, sobre todo su texto donde introduce "autonomía de la migración" en la revista de Razza Operaia (Moulier-Boutang 1992) y su traducción al alemán: http://www.grundrisse.net/grundrisse34/interview_mit_yann_moulierbouta. htm

${ }^{5}$ Uno de ellos es el proyecto de investigación militante y artístico de Transit Migration. Los resultados se divulgaron por varios movimientos sociales que trabajaban temas migratorios. En el libro que compila este proyecto, hay un capítulo referencial: "AdM: 10 tesis de una metodología" por Manuela Bojadžijev and Serhat Karakayal (2007: 203-209). 
Alemania entre 1950 y 1960 con programas gubernamentales. El colectivo de Kanak-Attak puso énfasis en los migrantes como sujetos políticos con voces propias y rechazó la "integración", como solución aparentemente humanitaria y políticamente correcta, pero sin embargo profundamente problemática (Hess, Binder, and Moser 2009). Esta nueva "mirada autónoma" articulada con campañas, intervenciones artísticas, y textos por el colectivo Kanak Attack, tuvo un eco en los movimientos sobre la precariedad y las fronteras que estaban a flote en Europa central y del Sur (Heidenreich and Vukadinovc 2008; Kanak Attak 2004). Muchos grupos a nivel local y Europeo acogieron esta visión en sus acciones y manifiestos: No One Is Illegal campaign, No Border Camps, Anti-Deportation Class, the Frassanito Network, y EuroMayDay. En el caso de Alemania, todo este resurgimiento político estaba íntimamente ligado a la producción académica y artística, a través de iniciativas colectivas como proyectos de mapeo institucional (Transit Migration); artísticos (An-architektur); redes de investigación entre trabajos con afinidad teórica/metodológica (Kritnet) y plataformas de publicación (revista Movements Journal for Critical Migration and Border Regime Studies).

También llamada Kanak-Operaismo, esta tradición puso la migración al frente del análisis y de la acción política. En cuanto al término italiano Operais$m o$, se refiere a la tradición política del Autonomismo que propone una lectura heterodoxa de Marx influida por teorías post-estructuralistas. Plantea las acciones de la clase trabajadora como instigadoras de las transformaciones en el capitalismo, cuyas restructuraciones se conciben como respuestas a las demandas y a las estrategias de los trabajadores.

\section{- La tradición política-teórica de la Autonomía en Italia}

Efectivamente, la Autonomía de la Migración y su visión de la movilidad humana como "fuerza primordial" surgen de la corriente del Autonomismo. Después de las revueltas estudiantiles de fines de los 60, emergía la posición autónoma liderada por movimientos de asalariados y de estudiantes que se rebelaban contra el vanguardismo y burocratismo de los partidos comunistas (Cuninghame 2010). En el caso Italiano, esta tradición política se denomina Operaismo, y contó con varios esfuerzos organizativos y expresiones intelectuales por la alta actividad de la izquierda extra-parlamentaria después de los movimientos hippies. La experiencia del 68 en Italia tuvo una duración larga, extendiéndose hasta finales de los 70. Además de las demandas de liberación cultural del 68 trabajando temas de ecología, género y antiautoritarismo, los movimientos italianos también propusieron la liberación de la disciplina de la fábrica y de la rutina de la oficina. Para ello exploraron conceptos y estrategias creativas como el "rechazo del trabajo" y la "investigación militante". Esta época de formas sociales de antagonismo no convencionales se ha bautizado con el término de "Laboratorio Italia" (Virno and Hardt 2010). Fue un momento histórico de máxima intensidad política con cambios repentinos en el gobierno italiano. La creatividad autono- 
mista no fue bien recibida ni por la izquierda institucional, ni por la derecha que muchas veces acusó a los autonomistas de terroristas, poniendo a muchos en la cárcel o en el exilio.

El Operaismo desarrolló, a nivel teórico y práctico, la tesis no-convencional de que las luchas obreras no responden, sino que preceden, a los desarrollos capitalistas. Así, los deseos y demandas de los trabajadores son apropiados y readaptados para que el sistema siga funcionando, en respuestas del sistema operando a modo de "contra-revolución" (Virno 2003). Esta centralidad de las acciones de los trabajadores explica el nombre de teoría "operaista". Esta teoría se ha ido complejizando con contribuciones feministas, y otras corrientes de la Teoría Crítica, inspirando a muchos intelectuales-activistas de la "Post-Autonomía" a analizar el ciclo actual del capitalismo como Post-Fordismo (de Bloois et al. 2014). La Autonomía y Post-Autonomía afirman que las transformaciones paradigmáticas en el trabajo son la respuesta a la "huida de la fábrica". Esta lectura de la flexibilidad de la producción propone la "precariedad" como una condición producida por el sistema, respondiendo a la movilidad de los trabajadores. Esta precariedad, aunque haya traído inseguridad e incertidumbre, también tiene potencialidades de fuga. Fue en este contexto de politización de la precariedad donde para Mezzadra surge la versión italiana de la "autonomía de la migración". Los movimientos de la precariedad realizaron debates durante los 1980 y 1990 en un momento donde Italia había descubierto que de manera abrupta se había convertido en un país de inmigración. Fue en esta coyuntura histórica donde se planteó si se podía interpretar la migración como un poder constituyente (Entrevista a Mezzadra 2011: 586). Del mismo modo que la autonomía clásica veía en las luchas obreras el motor del desarrollo capitalista, se intentó identificar la migración como un elemento dinámico que provocaba cambios socio-económicos.

\section{- Movimientos de la Precariedad in Spain}

De forma paralela la Autonomía española, bastante activa durante la última década del régimen franquista, criticaba a la izquierda tradicional de cosificarse en partidos políticos y estructuras sindicales obsesionados con llegar al poder estatal (López Petit and Fundación Espai en Blanc 2008; Sala, Durán, and López Petit 2016). Estas lógicas anti-autoritarias resurgieron durante las luchas de la precariedad. La crítica a la democracia representativa y a los sindicatos mayoritarios generó una extensa actividad organizativa sobre el tema de la precariedad en centros sociales, librerías y editoriales independientes, así como esfuerzos del auto-denominado "bio-sindicalismo" con Oficinas de Derechos Sociales y Agencias de Asuntos Precarios en varios puntos del país. Durante el desarrollo incipiente de sus propias instituciones y prácticas organizativas, las luchas de la precariedad, se enlazaron con el tema de la migración en iniciativas como la "Caravana a la Valla", el "Ferrocarril Clandestino", y Redes de Sin Papeles/Sin Fronteras en centros sociales/librerías/oficinas precarias (Pantera Rosa en Zaragoza, Hormiga Atómica en Iruña, Ateneu Candela en Terrasa, Casa Invisible en 
Málaga, Casa Invisible en A Coruña). El intento de pensar la precariedad junto a la migración tomó forma en proyectos de investigación y cartografía militante como "Precarias a la Deriva", "Precarity-Web-Ring", "Otra Málaga" o "Fadaiat". Textos nacidos al calor de estas iniciativas políticas híbridas entre el tema de la precariedad y la migración se publicaron en la revista Contrapoder, y en libros sobre pensamiento autónomo, investigación militante y luchas de inmigrantes publicados por editoriales alternativas y en código abierto como Traficantes de Sueños. Fue clave la llegada de dos teóricos principales de la AdM a través de la traducción y publicación por Akal de la obra de Boutang; y de la traducción de "el derecho a la fuga" de Mezzadra publicado por Traficantes de Sueños. ${ }^{6}$

Este breve repaso de la AdM en diferentes contextos nacionales sirve de ejemplo de cómo la AdM ha surgido al calor del encuentro de tradiciones intelectuales y políticas entre la Autonomía, las movilizaciones por comunidades migrantes y los debates sobre la precariedad. Más recientemente, un número creciente de académicos y activistas basados en diferentes partes del mundo han experimentado este paradigma de la Autonomía de la Migración, revigorizando debates universitarios y públicos sobre la migración. Esto incluye su implantación en la academia anglo-sajona (De Genova 2017) y latinoamericana (Cordero, Mezzadra y Varela 2019). También han aparecido redes internacionales trabajando la AdM desde diferentes geografías como es el New Keywords Collective (Casas-Cortes et al. 2014; De Genova et al. 2016). Estos debates recientes han llevado a la AdM, e incluso a la tradición del autonomismo en general, a encuentros con el pensamiento poscolonial, la tradición negra radical y el feminismo crítico. Un ejemplo explícito de esta comunión de tradiciones críticas es el libro

${ }^{6}$ El pensamiento de la autonomía de la migración estuvo vivo en territorios españoles como muestran múltiples iniciativas. Sin embargo, la Autonomía Española (incluida la relacionada con la migración) no suele tener representación y/o debate ni en el mundo académico ni activista a nivel internacional. Y el trabajo de múltiples colectivos y proyectos en este sentido no tuvo el mismo impacto en los estudios migratorios como puede ser en los casos de Alemania e Italia.

Personalmente, fue en el vibrar político e intelectual de este momento donde nosotros nos encontramos con la AdM, traduciendo partes del libro de Fadaiat (2006), donde se intentó hacer una interpretación de la frontera Sur utilizando la AdM. Este encuentro con textos como "Derecho a Fuga" nos llevó unos años más tarde a realizar una entrevista con Sandro Mezzadra publicada en Environment and Planning D, introduciendo su pensamiento sobre migración entre geógrafos anglosajones (2011). A partir de ahí, planteamos un proyecto de investigación postdoctoral sobre los flujos extra-comunitarios a Europa en parte inspirados en la tradición de la autonomía. El objetivo era entender el fenómeno de la externalización de la frontera Europea, desde el punto de partida del exceso y turbulencia de los flujos migratorios. De hecho, como parte de este proyecto pudimos contrastar el análisis de programas de cooperación policial entre países de la Unión Europea y África Occidental con nuestra participación en la Red de los Sin Paples de Zaragoza. Esas conversaciones y talleres durante las reuniones de la Red, el recontar y mapear las trayectorias de personas supuestamente interceptados en la frontera o detenidos a miles de kilómetros del territorio español, constituyó una fuente importante para el análisis de las ultimas políticas fronterizas de la Unión Europea desde un punto de vista no convencional con proposiciones como "las fronteras se estiran", "la pelea de cartografías en la producción de fronteras", "la guerra contra la movilidad" (Casas- Cortés, et al. 2015; Casas-Cortés et al. 2017; Casas- Cortés and Cobarrubias 2019). 
Border as Method (Mezzadra and Neilson 2013). El resultado de esta trayectoria es una multiplicación de versiones de la AdM, compartiendo una serie de conceptos clave que se exponen en la sección siguiente.

\section{Parte II: Conceptos Clave en la Autonomía de la Migración y algunas críticas}

a) El concepto de 'fuga'

El concepto de fuga se desarrolla en el libro De l'esclavage au salariat. Economie historique du salariat bride (1998), basado en la tesis del historiador, economista y militante Yann Moulier-Boutang, colaborador importante en la revistas políticas de Futur Anterieur y Multitudes. La traducción en castellano consta de mil veintitrés páginas de análisis histórico y reflexión en términos de teoría económica. A través de un estudio detallado sobre los tipos de trabajo y contratación desde el siglo XVI al XX en Europa central, en el mercado transatlántico de esclavos y en numerosas colonias, Boutang confirma una primera hipótesis, o intuición, sobre la formación del capitalismo global:

" ¿Cual es el principio primordial? El control de la fuga de los trabajadores dependientes representa el elemento principal que ha gobernado el nacimiento, deterioro, y reemplazo de las diversas formas de trabajo no libre, así como la génesis de la protección social y del estatuto del trabajo asalariado libre y protegido, tal y como ha sido edificado en el código de trabajo (...) La fuga del trabajo dependiente, libre o no libre, se nos ha presentado como el primum mobile no sólo de la creación, de las deformaciones así como de la destrucción de las instituciones históricas del mercado laboral, sino también de la competencia capitalista y de la acumulación en general." (Moulier-Boutang 1998/2006: 32)

Siguiendo esta interpretación, la economía mundo ha generalizado el mercado de trabajo asalariado, normalizando relaciones de dependencia económica condicionadas unilateralmente. El primum mobile para llegar a esta aceptación del blackmail (chantaje laboral) ha sido la búsqueda de mecanismos legales para controlar la huida, y por tanto para evitar la ruptura de la relación laboral, ejercida por parte de siervos, esclavos, engagés, y los 'sin propiedad' de manera constante en diferentes periodos históricos y geografías. En comparación con sistemas previos, el capitalismo se presenta como portador de la libertad pues el trabajo asalariado requiere del acuerdo entre personas jurídicamente "libres". Sin embargo, Boutang descifra como el trabajo asalariado constituye la solución buscada por los que necesitan mano de obra leal, sedentaria o al menos predecible, queriendo evitar o reducir el constante movimiento de las personas. De este modo, son las prácticas cotidianas de la "fuga" las que fuerzan a desarrollar los contratos actuales, como mecanismos para controlar y gestionar la movilidad.

Para Boutang (1998/2006), las formas actuales de contrato y derecho laboral que representan la generalización del 'trabajo libre' se desarrollan a través de 
una larga historia de tira y afloja entre fuerzas políticas y económicas. En su sentido de dinámicas entre clases, es una interpretación marxista. Para Boutang, las cuestiones legales, las geografías políticas de jurisdicción (como las soberanías nacionales), y los contratos laborales, no son cuestiones meramente super-estructurales, sino intrínsecamente ligadas a las formas específicas de producción y de regulación social de coyunturas históricas concretas. Sin embargo, su interpretación tampoco está totalmente dentro de la Escuela Regulacionista, en cuanto que no ve las regulaciones simplemente como un paquete que automáticamente facilita nuevos modos de producción. Boutang critica explícitamente la rapidez de las conclusiones de los regulacionistas que pueden establecer equivalencias entre cada modo de producción y cada modo de regulación. Entonces, los cambios en las formas de trabajo (esclavo, embridado, o libre); el desarrollo del contrato laboral; y la evolución de la ciudadanía política y territorial, son resultado de un continuo proceso de tensiones y resoluciones no exclusivamente en el ámbito de lo público sino también lo cotidiano. Boutang desarrolla un detallado análisis histórico de longue durée en el segundo capítulo: "El continente de la fuga", sobre esta distinción clave entre la enunciación pública (voice) y prácticas cotidianas de la movilidad (exit o escape). Boutang distancia su análisis de las interpretaciones que se centraban en ciclos de lucha notorios que visibilizaban un malestar colectivo, como por ejemplo: las movilizaciones por las ocho horas, por el derecho a sindicato o por la abolición a nivel legal de la esclavitud. Aunque no les resta su importancia, para Boutang la principal vía de cambio y fuerza en estos procesos ha sido no tanto través de la "voz", sino de la "fuga" (MoulierBoutang 1998/2006: 12 and 32). De este modo, para Boutang, la mayoría de las "luchas migrantes" no se encuentran en la esfera de lo público, ni tampoco son claramente visibles con reclamaciones directas y explícitamente enunciadas a una estructura de poder. Los autores Papadapolous, Stephnson and Tsianos en su volumen Escape Routes, también insisten en la capacidad constituyente de la fuga, y en su importancia como punta de partida de cualquier análisis de las movilidades y del poder. Autores autonomistas, como Hardt and Negri, hablan en términos de "the primacy of escape", es decir, la "primacía de la huida":

"La historia fragmentada del vagabundear no es marginal a la historia de la soberanía; es un caso sintomático que ejemplifica como la primacía de la huida provoca las condiciones para pensar en su control dentro de la esfera de la producción y del trabajo en el Estado nación moderno." (Hardt and Negri 2000 en Papadapolous et al 2008: 43)

Para estos autores entonces la 'fuga' (escape) de las personas se convierte en "fuerza constituyente" (o al menos co-constituyente), en un proceso que presiona y transforma las formas de producción, de poder político, de legislación, etc.:

"La huida crea una forma de energía que potencialmente rompe el equilibrio de un régimen existente de control; entonces, un nuevo régimen de control necesita establecerse para apropiarse de esta energía y transformarla en una nueva subjetividad social manejable y cuantificable.'(Papadapolous et al.: 43) 
Papadapolous et alter no limitan su concepto de "escape", o fuga, a la movilidad humana, aunque ésta tiene una posición central en su análisis. Además, es importante subrayar que no cada forma de movilidad humana constituye una fuga, sino que las formas de movilidad no se registran en un régimen de "representación." Aunque la huida tiene la capacidad de transformar un régimen de control, "escape" a nivel estructural (no necesariamente individual) no constituye un "acto de resistencia" en sí o a priori:

"Ninguna huida se concibe como pura subversión. La huida siempre está situada y se desenvuelve en un proceso ambivalente [...] La huida no es una propuesta, sino una construcción desde el disentir." (Papadapolous et al 2008: 59-61)

Escape Routes se enfoca en la fuga y la movilidad como fuerzas productivas tanto para procesos de resistencia como configuraciones del poder (Papadopoulos et al. 2008:82, 203). Según un autonomista estadounidense, Stephan Shukaitis, este trabajo de Escape Routes introduce el concepto de "políticas imperceptibles" en el tema de la migración como una esfera de la acción colectiva fuera de las lógicas de derechos y representación, "adaptando la idea central de la autonomía sobre la resistencia como ontológicamente primera y determinante" (Shukaitis 2012: 425).

\section{b) La migración como motor de políticas fronterizas, laborales y de ciudadanía}

"La autonomía de la migración es crítica de cualquier intento de representar a las fronteras como muros impenetrables. Este enfoque insiste en re-imaginar y repensar la realidad de la frontera y su relación con la migración." (Nyers 2015: 28)

Partiendo del análisis de la fuga como fuerza constituyente, el marco de la AdM insiste en considerar la migración como algo previo al 'control migratorio' y sus políticas fronterizas. Aunque la migración está profundamente afectada por las restricciones fronterizas, ontológicamente, primero existe la movilidad y después las fronteras. En las palabras de dos miembros del colectivo Kanak Attak:

"Un aspecto importante de esta perspectiva crítica es que cuestiona el presupuesto de que las políticas migratorias están exclusivamente determinadas por los Estados y por las instituciones de control fronterizo... El régimen de frontera no se transforma a su propio ritmo, pero obtiene su dinámica de las formas de los movimientos migratorios”. (Bojadžijev and Karakayali 2010:1)

Esta interpretación no quiere decir que las políticas migratorias no tengan un efecto profundo en los trayectos migratorios y en las vidas de personas en movimiento. Al contrario, aunque la AdM reconoce y critica sus abusos sobre personas y ataques indiscriminados a los derechos humanos, la AdM sobre todo enfatiza la ineficacia de las fronteras. Es decir, las políticas fronterizas por sus propios límites de diseño y puesta en práctica, no logran acaparar todas las fases migratorias, posibles itinerarios y direcciones de la movilidad humana. 
"Mientras las políticas e instituciones de gestión migratoria normalmente irrumpen violentamente las vidas y formas de vida de los migrantes, sus esfuerzos de gestión finalmente se quedan cortos por las disyuntivas entre prácticas de control y diversidad de flujos que buscan regular". (Casas-Cortés et al. 2014: 897-8)

La movilidad humana entonces se considera tan diversa y continua, adaptable y cíclica, que es difícil de cuantificar y describir con absoluta precisión, por eso se habla en términos de "exceso" de las migraciones. Dicho exceso fuerza a los Estados a adaptarse en sus procesos de regulación y control, realizando mutaciones legales que crean nuevos niveles de gobierno y arreglos institucionales. Entonces la política fronteriza responde estratégicamente a la agencia colectiva de las migraciones, entendida como "fuerza creativa", en un proceso de rearticulación de control de poblaciones dirigido a categorizar tipos de cuerpos en movimiento y regular diversas formas de movilidad:

"En el proceso, estas configuraciones están forzando repensar muchos de los significados convencionales de soberanía y ciudadanía. De hecho, con las prácticas de externalización fronteriza, y el aumento en la cooperación internacional en temas de política migratoria, se puede decir que, según la AdM, las migraciones actuales están forzando una reformulación a nivel transnacional de régimen migratorio." (Entrevista a Mezzadra 2011: 591)

Mezzadra insiste que la migración siempre está retando a sus controles, y que las políticas fronterizas y prácticas de exclusión no están exclusivamente gestionadas por el Estado y la ley. El Estado reacciona a la migración, y los movimientos migratorios constituyen la fuente de los cambios en el sistema fronterizo.

c) Críticas más comunes: ¿La romantización de la migración en la AdM?

Estos mismos planteamientos teóricos, 1) la centralidad de la fuga, y 2) la migración como motor de transformaciones políticas, pueden entenderse de manera que la movilidad humana cobra un inusitado protagonismo histórico. Desde esta lectura, la figura del migrante aparece incluso con cierta heroicidad. Esta es una de las críticas más comunes entre los que aunque reconocen cierta innovación en la teoría de la AdM, identifican una glorificación injustificada de las migraciones: critican que estos planteamientos pueden llevar a una problemática romantización de los/las migrantes. Ligada a esta cuestión, las críticas apuntan a una reducción analítica de las singularidades de las diversas experiencias de movilidad bajo la categoría genérica de "migrante". En su forma más exagerada, los/las migrantes se convierten en un tipo de 'nuevo sujeto revolucionario' (Mezzadra and de Genova 2015). Aunque existe este posible riesgo, sin embargo, esto es debido en parte a que 'autonomía' se confunde con una noción liberal de la autonomía (tanto en las críticas como a veces hasta en quienes emplean la AdM en sus estudios). Se interpreta como la libertad individual para tomar decisiones en situaciones específicas, presuponiendo individuos o familias sopesando con cálculos de cómo traspasar las trabas de regímenes fronterizos en su caso parti- 
cular (asemejándose al concepto de agency). Desde esta lectura, tanto los efectos negativos del poder estatal en gestionar la movilidad humana, como la ambivalencia de las decisiones migratorias, se minimizan en una saga de "migrantes sufrientes vs. fronteras violentas".

Para el geógrafo Boyce en reacción a la Autonomía de la Migración, afirma que la interpretación autónoma de las prácticas migratorias "contiene el riesgo de romantizar la migración clandestina como un indicador axiomático de resistencia, sin tener en cuenta el tremendo sufrimiento y violencia que a menudo acompañan a estas prácticas; las consecuencias destructivas para vidas humanas; [...]" (Boyce 2018: 347).

Aunque la noción de autonomía no liberal puede proveer de una crítica más dinámica a los procesos de poder y contra-poder, el prisma de la autonomía de la migración en su análisis del desarrollo del poder estatal y de las relaciones laborales también es criticada por otro posible defecto. Se trata de la reducción de las millones de personas que migran, en condiciones radicalmente distintas, en la categoría genérica de "migrante". Muchos de los autores de la AdM están trabajando con y a la vez en contra de las categorías utilizadas por las agencias fronterizas (Irregular, buscador de asilo, migrante económico, etc.) y en este proceso, puede realizarse una reificación de esas mismas categorías bajo la noción de "migrante". En el mismo esfuerzo de retar estas categorías, algunos críticos mantienen, que la AdM puede terminar por caer en una generalización parecida. Sharma, en su análisis del trabajo de Papadapous, Stephenson y Tsianos señala precisamente este peligro en la AdM:

"Los 'migrantes' en Escape Routes están principalmente tratados de manera genérica [ ]. Los cientos de millones de personas reales que migran están constantemente agrupados y asignados bajo el término de 'migrantes.' [...] No se aborda tampoco el acceso diferenciado a la "huida". Migrantes y fugas se convierten en abstracciones categóricas" (Sharma 2009: 474)

Es cierto que el lenguaje filosófico y poético de estos autores, inspirados en la tradición de Deleuze, es novedoso en su rescate analítico de los migrantes que ya no son solo "recipientes" de política fronteriza y "objetos" de gestión migratoria, sino activos co-constituyentes de regímenes de poder. Sin embargo, su lenguaje casi literario puede excederse en generalizaciones que Sharma critica como limitaciones, y quien además apunta que no debería hacerse incluso en la tradición Deleuziana de análisis social:

"Tratar a los migrantes de manera categórica resulta en el tipo de romantización orientalista que Deleuze y Guattari ya avisaron de evitar en su obra de Nomadology: The War Machine." (Sharma 2009: 474)

Esta crítica de la Autonomía es pertinente en el caso de algunos autores y para evitar simplificaciones. Sin embargo, los escritos de la Autonomía ${ }^{7}$ de la Migración varían en su tradición disciplinar y estilo expositivo.

${ }^{7}$ Cuando se lee a Boutang, por ejemplo, se trata de un estudio histórico de larga duración, analizando material de archivos en clave de economía política. Mezzadra tiene una fundación 
Otra crítica relacionada a la romantización consiste en cuestionar la centralidad de la movilidad como motor de cambio. Proponer a la movilidad en términos de "iniciar transformaciones" se inspira en el pensamiento de Foucault sobre las relaciones de poder, donde la resistencia es ontológicamente primera. Sin embargo, el vocabulario temporal (inicio o primero), da cabida a una confusión sobre el concepto de primordialidad. Para McNevin (2013) and Nyers (2015), algunos teóricos de la Autonomía (citan directamente a Papadopoulos, Hardt y Negri, y De Genova) interpretan el 'poder' de una manera demasiado reduccionista donde la migración, e incluso las luchas migrantes se constituyen como un 'afuera' cuestionable:

"El problema con esta perspectiva reduccionista es que no refleja las maneras en que el control y la resistencia son co-constituyentes, cada una produciendo y transformando a la otra." (Nyers 2015: 33)

Para McNevin, la migración es una fuerza que reconstituye el carácter de la frontera y la ciudadanía a través de sus acciones en interacciones con poderes soberanos. La migración no es tanto un afuera sino que incluso forma parte de esos poderes:

"La "primacía de la movilidad" sobre el control tiene la tendencia de representar la migración como un movimiento social que resiste la incorporación en sistemas administrativos del sistema estatal moderno." (McNevin 2013: 192)

Para McNevin, las lecturas de la AdM que se centran en la ambivalencia de la migración pueden evitar que la autonomía se limite a la "acción individual" de personas categorizados como migrantes. En esto McNevin se enfoca en el trabajo de Sandro Mezzadra como un ejemplo de las posibilidades que abre la AdM cuando evita explícitamente la romantización de los "migrantes" y no esencializa el "poder" como un "afuera", algo exterior a la movilidad humana.

"Dado que algunos teóricos de la AdM han sido criticados por romantizar la migración, es importante añadir que siempre hemos tenido en cuenta la ambivalencia de estas prácticas subjetivas." (Entrevista a Mezzadra 2011: 587)

Mezzadra, de manera más explícita, y otros teóricos de la Autonomía de la Migración, retan el punto de vista que enfatiza la capacidad de los poderes establecidos (Estados, empresas, etc.) como único factor que define procesos en curso. Al contrario, enfatizan las experiencias de movilidad como expresiones de resistencia y de co-construcción de políticas y prácticas tanto fronterizas como laborales, y legislativas.

teórica critica en estudios Post-Coloniales que es evidente en su manera de escribir y en su uso de referencias teóricas. De la misma manera Poupadopulus et al., también se fundamentan en un análisis teórico riguroso, pero al mismo tiempo provocativo, con el objetivo de trasgredir conceptos asumidos difíciles de cuestionar. De Genova realiza su exposición desde una metodología etnográfica dentro de su campo de Antropologia cultural influida por teorías post-estructurales. 
Aun así, los análisis de Boyce, Sharma y McNevin señalan importantes peligros y posibles lagunas en algunas interpretaciones de la AdM. El experto en Estudios de la Ciudadanía, Peter Nyers, también ha subrayado la importancia de la AdM en señalar el dinamismo de la migración como transformador de regímenes territoriales de soberanía, pero también sus límites a la hora de entender como transforma la 'ciudadanía' dado que varios autores actuales en la AdM descartan a la ciudadanía como categoría excluyente (Nyers 2015: 23). Mientras que estas críticas están bien fundadas, sin embargo no parecen dialogar de manera extendida con el largo trabajo de autores alemanes y franceses que han estado trabajando desde esta perspectiva en investigaciones etnográficas, históricas, legales y cartográficas (esto puede ser en parte a una cuestión de traducciones y falta de dialogo entre tradiciones académicas nacionales). Se podría decir que la llegada de la Autonomía a la academia (sobre todo la anglo-sajona) ha ignorado sobre todo los planteamientos de Boutang, especialmente su contribución sobre el fenómeno histórico de la Autonomía. Boutang propone la autonomía no como algo heroico o totalmente 'fuera' de un régimen de poder, de relaciones de ciudadanía y/o contrato, sino identificando como la movilidad constituye una dinámica visible cuando se toma una postura de longue durée. Para Boutang, la autonomía emerge como factor cuando uno tiene en consideración la transformación del sistema-mundo (Boutang dialoga con la teoría del sistema mundo de Wallerstein, y con el enfoque de larga duración de Braudel) y la formación de las características modernas de clases social, ciudadanía estatal y contrato laboral. Las luchas continuas sobre movilidades humanas, y sobre todo la fuerza de trabajo, co-constituyen los parámetros actuales de la clase y la ciudadanía y para Boutang esta dinámica no se pueden ignorar.

\section{4. “BORDER AS METHOD”: FRONTERA COMO METODOLOGÍA Y APLICACIONES DE LA AUTONOMÍA DE LA MIGRACIÓN A ESTUDIOS DE CASO}

Además de entender la migración de otra manera, la AdM defiende el valor analítico de la movilidad como punto de partida para entender las transformaciones fronterizas y de política migratoria. Incluso, algunos autores sostienen que este enfoque puede ayudar a analizar cambios socio-económicos y políticolegales en curso. Para un desarrollo teórico y analítico de esta propuesta el libro de Border as Method (2013) de Sandro Mezzadra y Brett Neilson es clave. El volumen examina la proliferación de fronteras y las dinámicas de movilidad y fuga para analizar las reconfiguraciones en la economía, el Estado, la jurisprudencia y la gobernanza a nivel global. En este sentido, inspirándose en los análisis de la AdM para formar un punto de vista epistemológico diferente hacia la denominada globalización.

Pero a parte de estas reflexiones teóricas, queremos subrayar brevemente los estudios de caso donde se utiliza la teoría sobre la Autonomía de la Migración contribuyendo a un giro metodológico y/o epistemológico en los estudios 
migratorios y los estudios de fronteras. En este sentido, existen una serie de trabajos donde se "aplica" la teoría de AdM para entender una serie de fenómenos concretos en las dinámicas fronterizas y de migración. Estos incluyen investigaciones empíricas sobre temas varios: controles fronterizos biométricos (Scheel 2013a, 2013b); la primavera árabe (Tazzioli 2015; Garelli and Tazzioli 2017); e incluso el replanteamiento de regiones geopolíticas, como Latinoamérica (De Genova 2017). ${ }^{8}$

Un estudio donde participamos, Riding Routes (Casas-Cortes, Cobarrubias and Pickles 2014), analiza el fenómeno de la externalización de fronteras de la Unión Europea en territorios extra-comunitarios desde la AdM. En concreto, nos centramos en el desarrollo de la estrategia de "gestión de rutas migratorias" de la UE y su implementación por parte de España en ciertos países africanos. La externalización -sobre todo en su versión policial- se puede entender como la 'fuerza dura' (hard power) del Estado intentando expandir su campo de acción de forma preventiva y extraterritorial. A menudo se percibe como una acción cuyo motor es la iniciativa soberana de controlar flujos de personas. Riding Routes pregunta ¿qué ocurre si intentamos interpretar la externalización con dos puntos centrales de la AdM -la centralidad de la fuga y la migración como motor de cambios- para entender cómo y porqué ha sucedido el proceso geopolítico de acuerdos de cooperación transfronteriza entre España, la UE y países del Norte y Oeste de Africa? La selección de países para cooperar, el intento de trazar una geografía de itinerarios concretos y de segmentar esos itinerarios en puntos de "origen, tránsito y destino", demuestran un continuo tira y afloja de los procesos complejos y variados de migración, intentando hacer gobernable algo que se presenta como 'caótico', y luego ajustando categorías previas cuando estas no funcionan.

Nuestro estudio en vez de observar las rutas de migrantes en territorios extraeuropeos, se centra en la proliferación de 'check-points', de puestos de control migratorios que precisamente no están situados en la línea fronteriza, sino a miles de kilómetros en el Sáhara o en el Atlántico. Estas prácticas fronterizas de control remoto obtenían su dinámica espacial y política de la percepción de los cambios en las rutas migratorias, aunque esas rutas siempre apareciesen en permanente cambio, mucho más variadas y complejas que los propios intentos institucionales de cartografiarlos y gestionarlos. Nuestro enfoque trata de responder al reto expuesto por la AdM de ir más allá del análisis de la migración en sí como objeto de estudio y tomarlo como plataforma para estudiar dispositivos de poder (2014: 897).

Según el trabajo histórico de Torpey (2000), el Estado no solo ostenta el monopolio de la violencia legítima, sino también ejerce el monopolio de dictar

${ }^{8}$ Es importante mencionar aquí que la mayoría de los estudios que utilizan AdM como marco teórico se aplican a casos de migración hacia o en la Unión Europea. Aunque no sea el caso del estudio histórico de Boutang, una limitación actual de la autonomía de la migración es como esta mirada teórica dialogará con otros contextos geográficos. La reciente aportación de Cordero et al. (2019) en pensar la Autonomía de la migración en el contexto Latinoamericano ayuda a corregir esta brecha geográfica. 
y garantizar los movimientos que considera legítimos. Basados en esta lectura, en nuestro análisis de la externalización de fronteras desde una perspectiva de la AdM, hemos planteado entender la "frontera desplazada", no solo como un límite a las capacidades migratorias, sino:

"La frontera como un espacio de contestación en el cual el Estado se esfuerza, aunque falla a menudo, en mantener su compromiso ficticio de total soberanía territorial, entendida como su capacidad de ejercer sus "derechos" sobre las poblaciones que transitan en sus territorios, y de implementar su monopolio en establecer movimientos legítimos "(2014: 898).

Los continuos ajustes en las políticas de externalización demostraban que éstas respondían principalmente a los cambios en los itinerarios migratorios y a estrategias de movilidad humana, sin restar importancia a los niveles de cooperación entre los diferentes estados involucrados. El intento de trazar estas rutas llevó a cabo un proceso de re-imaginación de espacios y regiones geopolíticas y el despliegue de instrumentos diplomáticos, presupuestarios y policiales reconfigurando las relaciones internacionales en la zona. Una observación que se asemeja a la propuesta de la AdM de entender la migración como un motor de cambios, incluso en campos no relacionados directamente con la migración.

\title{
4. A MODO DE CONCLUSIÓN: BAILANDO SIN FRONTERAS
}

\author{
¡Ala, iros! \\ Iros y decid al gobierno porqué la juventud en este país quiere ir a Roma. \\ Por avión, barco o en patera, todo el mundo se fuga \\ de los rostros de esa gente (corrompidos en el poder). \\ ¡Pues iros a por ello! \\ ¡Ala, iros! I-iiii-ros!
}

Un año antes de la Primavera Árabe, el músico Lotfi Double Kanon de Argelia lanza una canción que captura un aspecto clave de la AdM. El estribillo llama a los jóvenes argelinos a irse del país varias veces repitiendo la palabra "ruh!" - imperativo en plural del verbo "ir" en árabe y que también significa viento. ${ }^{9}$ Esta invitación a "marchar", a dejar el país en avión, en barco o en patera, como forma de descontento y resistencia al autoritarismo y problemas internos del país apunta a la noción autónoma del migrar como acto político. En sus letras la opción de emigrar no es un acto de desesperación (a pesar de las condiciones difíciles que lo pueden ocasionar), sino que se contextualiza como un acto de protesta llevado a cabo por muchos. Otra canción de cómo los propios migrantes y refugiados llaman a "saltar la valla", literalmente, es el rap Jump In de M.I.A., la refugiada de Sri Lanka basada en Londres. ${ }^{10}$ Su otra canción aún más polémica,

${ }^{9}$ Video musical con las letras en árabe y en inglés esta accesible en: http://revolutionaryarabraptheindex.blogspot.com/2011/11/lotfi-double-kanon-7oukouma.html

${ }^{10}$ Jump in https://www.youtube.com/watch?v=Wq-Nkh3ELpI 
también del álbum Aim (Propósito) lanzado en 2016, es Borders. ${ }^{11}$ Con su larga lista de cuestionamientos ("freedom, what's up with that? Identities, what's up with that?") muestra una postura de casi "orgullo migrante" que muy bien puede ligarse a los principios de la Autonomía de las Migraciones: la centralidad de la migración, tanto a nivel analítico como político. En este sentido, la canción invita a repensar categorías como identidad, libertad y familia pensando desde las fronteras y la vivencia migratoria.

La Autonomía de la Migración surge como una manera de entender la migración como una fuerza dinámica en las sociedades que contribuye y transforma otros procesos culturales, políticos e incluso económicos. El contexto de donde surge inicialmente, marca de manera importante sus planteamientos: un contexto de autores y colectivos muy involucrados en luchas, tanto cotidianas como explícitas, de personas marcadas como "migrantes y extranjeros", teniendo que navegar esos terrenos. Esa situación conlleva a que una serie de preguntas diferentes marcaran el desarrollo de la AdM; se alejará de estudiar los porqués y los cómos de la migración, para entender las maneras en que la migración responde y condiciona las sociedades actuales. Las prácticas de movilidad y de supervivencia de migrantes se estudiarán con un prisma algo distinto a los estudios de diáspora y trans-nacionalismo (con los cuales puede compartir varios presupuestos) y en claro contraste con los estudios enmarcados hacia la integración como un bien sin problematizar. La migración, desde la AdM, se entiende entonces como un campo clave donde entender los límites y cambios de conceptos como ciudadanía, raza, comunidad, y derechos entre otros. La dinámica entre movilidad y fronteras subrayado por la AdM puede, según sus autores, vislumbrar estructuras sociales en proceso de transformación, como nos indica la propuesta de Border as Method. Con lo cual, el estudio de la migración va mucho más allá del estudio de la re-producción o manutención de identidades étnicas o la integración en mercados laborales y marcos legales nacionales.

Este artículo intenta presentar la AdM como una propuesta teórica, con importantes implicaciones metodológicas y epistemológicas, para tener en cuenta en los estudios migratorios en España. Aunque la AdM sí tiene una trayectoria en España, su presencia en los estudios migratorios es mínima. Este artículo resume de forma breve su contexto histórico y su genealogía conceptual, sus planteamientos claves y sus críticas, contribuyendo a un posible debate sobre sus posibilidades en un contexto académico donde este marco teórico no se ha implantado.

En términos políticos, la literatura de la AdM ofrece una ética no utópica de "no-borders", infiriendo que un mundo sin fronteras es factible, necesario, eficiente y deseado. Y por lo tanto llama a "una mirada desobediente" sobre los controles aduaneros y fronterizos (Nyers 2015). ${ }^{12}$ Con estos videos musicales

${ }^{11}$ Borders http://www.humanosphere.org/basics/2015/12/refugee-crisis-m-s-powerful-songvideo/

12 "Desobediencia" es una estrategia de la tradición autónoma que se traslada al activismo sobre la migración. Se llama a desobedecer las fronteras como una manera de asegurar la libertad 
terminamos esta breve presentación de un "paradigma-otro" para pensar la movilidad humana, el cual esperamos que esté saliendo poco a poco de su ámbito contra-cultural para inspirar a muchos en la academia y más allá.

\section{BIBLIOGRAFÍA}

Balibar, Étienne. 2009. We, the People of Europe?: Reflections on Transnational Citizenship. Princeton University Press.

Bloois, Joost de, Monica Jansen, Frans Willem Korsten, Matteo Pasquinelli, Stevphen Shukaitis, Maribel Casas-Cortés, Vittorio Morfino, and Robert Wells. 2014. "PostAutonomia." Rethinking Marxism 26 (2): 162-162. https://doi.org/10.1080/089356 96.2014.888829.

Bojadžijev, Manuela, and Serhat Karakayali. 2010. "Recuperating the Sideshows of Capitalism: The Autonomy of Migration Today I e-Flux." E-Flux Journal, 17. 2010. http://www.e-flux.com/journal/recuperating-the-sideshows-of-capitalism-the-autonomy-of-migration-today/.

Boyce, Geoff. 2018. "Autonomy, Human Vulnerability and the Volumetric Composition of US Border Policing." In Handbook on the Geographies of Power, edited by Mat Coleman, 347-61. Research Handbooks in Geography Series. Northampton, MA: Edward Elgar Pub., Inc.

Casas- Cortés, Maribel, Sebastian Cobarrubias, Nicholas De Genova, Glenda Garelli, Giorgio Grappi, Charles Heller, Sabine Hess, et al. 2014. "New Keywords: Migration and Borders." Cultural Studies 29 (1): 55-87.

Casas-Cortés, Maribel, Sebastian Cobarrubias, Charles Heller, and Lorenzo Pezzani. 2017. "Clashing Cartographies, Migrating Maps: The Politics of Mobility at the External Borders of EUrope." ACME: An International Journal for Critical Geographies 16 (1): 1-33.

Casas- Cortés, Maribel, Sebastian Cobarrubias, and John Pickles. 2015. "Riding Routes and Itinerant Borders: Autonomy of Migration and Border Externalization." Antipode 47 (4): 894-914. https://doi.org/10.1111/anti.12148.

Casas- Cortés, Maribel and Sebastian Cobarrubias. 2019. "A War on Mobility: The Border Empire Strikes Back?" in Ways of Knowing Cities. NYC: Columbia Books on Architecture and the City

Chueca-Sancho, Ángel G.. 2010. Derechos humanos, inmigrantes en situación irregular y Unión Europea. Lex Nova.

Cuninghame, Patrick. 2010. "Autonomism as a Global Social Movement.” WorkingUSA 13 (4): 451-64. https://doi.org/10.1111/j.1743-4580.2010.00305.x.

De Genova, Nicholas, ed. 2017. The Borders of "Europe": Autonomy of Migration, Tactics of Bordering. Durham, NC: Duke University Press.

De Genova, Nicholas. 2013b. "'We Are of the Connections': Migration, Methodological Nationalism, and "Militant Research." Postcolonial Studies 16, no. 3: 250-58.

De Genova, Nicholas. 2005. Working the Boundaries: Race, Space, and "Illegality" in Mexican Chicago. Durham, N.C: Duke University Press.

de movimiento . Ver "Politics of Disobidience" en http://spheres-journal.org/politics-of-disobedience-ensuring-freedom-of-movements-in-a-bordered-world/ 
De Genova, Nicholas, Martina Tazzioli, Soledad Álvarez-Velasco SAV, Nicholas De Genova NDG, Charles Heller CH, Irene Peano IP, Lisa Riedner LR, et al. 2016. "Europe/Crisis: New Keywords of 'the Crisis' in and of 'Europe." Near Futures Online. https://pure.uva.nl/ws/files/9242843/PDF_New_Keywords_Collective_12. pdf.

Fadaiat-Colectivo. 2006. Fadai'at: Libertad de Movimiento+Libertad de Conocimiento. Malaga: Imagraf Impresiones

Fernández Sola, Natividad, ed. 2018. Fronteras Del Siglo XXI: Obstáculos o Puentes?: In Memoriam Profesor Ángel G. Chueca Sancho. Homenajes \& Congresos. Valencia: Tirant lo Blanch.

Garelli, Glenda, and Martina Tazzioli. 2017. Tunisia as a Revolutionized Space of Migration. Mobility \& Politics. New York: Palgrave Macmillan.

Genova, Nicholas De. 2017. "The Incorrigible Subject: Mobilizing a Critical Geography of (Latin) America through the Autonomy of Migration." Journal of Latin American Geography 16 (1): 17-42. https://doi.org/10.1353/lag.2017.0007.

Heidenreich, Nana, and Vojin Sasa Vukadinovc. 2008. "In Your Face: Activism, AgitProp, and the Autonomy of Migration; The Case of Kanak Attak." In After the Avant-Garde: Contemporary German and Austrian Experimental Film by Randal Halle, pp.131-156. Camden House, Rochester NY.

Hess, Sabine, Jana Binder, and Johannes Moser, eds. 2009. No Integration?! Kulturwissenschaftliche Beiträge Zur Integrationsdebatte in Europa. Kultur Und Soziale Praxis. Bielefeld: Transcript.

Kasparek, Bernd. 2016. "Routes, Corridors, and Spaces of Exception: Governing Migration and Europe." Near Futures Online, no. 1. http://nearfuturesonline.org/routescorridors -and-spaces-of-exception-govern-ing-migration-and-europe.

López Petit, Santiago, and Fundación Espai en Blanc, eds. 2008. Luchas autónomas en los años setenta: del antagonismo obrero al malestar social. 1. ed. Historia 8. Madrid: Traficantes de Sueños.

Mezzadra, Sandro. 2001. Diritto di fuga: Migrazioni, cittadinanza, globalizzazione (The Right to Escape: Migration, Citizenship, Globalization). Verona: Ombre Corte.

Mezzadra, Sandro. 2011. "The Gaze of Autonomy: Capitalism, Migration, and Social Struggles." The Contested Politics of Mobility: Borderzones and Irregularity, 12142.

Mezzadra, Sandro, and Brett Neilson. 2013. Border as Method, or, the Multiplication of Labor. Durham, NC: Duke University Press.

Mezzadra, Sandro and Nicholas de Genova. 2015. "Borders, Citizenship and Mobility," Conferencia pública. King's College, Londres, 26 de junio.

Mitropoulos, Angela. 2011. "Shift Magazine » Issue 10 No Borders » Interview with Angela Mitropoulos.” January 2011. http://shiftmag.co.uk/?p=385.

Mitropoulos, Angela. 2006. "Autonomy, Recognition, Movement." Commoner, no. 11: 5-14. Reprinted in Stevphen Shukaitis, David Graeber, and Erika Biddle, eds., Constituent Imagination (Edinburgh: AK Press, 2007), 127-36.

Moulier-Boutang. 1992. "Razza Operaia." 1992. http://www.sbn.it/opacsbn/ opaclib?db=solr_iccu\&nentries=1\&resultForward=opac $\% 2$ Ficcu $\% 2 F f u l l . j s p \& s e a r c$ hForm=opac\%2Ficcu $\% 2$ Ferror.jsp\&do_cmd=search_show_cmd\&saveparams=fals e\&rpnlabel $=+$ Soggetti+\%3D+IT\%5CICCU $\% 5$ CCFIC $\% 5$ C062354+\&rpnquery $=\% 2$ 540attrset $\% 2 \mathrm{Bbib}-1 \% 2 \mathrm{~B} \% 2 \mathrm{~B} \% 2540 \mathrm{attr} \% 2 \mathrm{~B} 1 \% 253 \mathrm{D} 8021 \% 2 \mathrm{~B} \% 2540 \mathrm{attr} \% 2 \mathrm{~B} 4 \%$ $253 \mathrm{D} 1 \% 2 \mathrm{~B} \% 2522 \mathrm{IT} \% 255 \mathrm{C} \% 255 \mathrm{CICCU} \% 255 \mathrm{C} \% 255 \mathrm{CCFIC} \% 255 \mathrm{C} \% 255 \mathrm{C} 06235$ $4 \% 2522 \& \&$ fname $=$ none $\&$ from $=1$. 
Moulier-Boutang, Yann, and Jean-Pierre Garson. 1984. "Major Obstacles to Control of Irregular Migrations: Prerequisites to Policy." International Migration Review 18 (3): 579 . https://doi.org/10.2307/2545887.

Nyers, Peter. 2015. "Migrant Citizenships and Autonomous Mobilities." Migration, Mobility, \& Displacement 1 (1): 22-37. https://doi.org/10.18357/mmd11201513521.

Papadopoulos, Dimitris, Niamh Stephenson, and Vassilis Tsianos. 2008. Escape Routes : Control and Subversion in the Twenty-First Century. London ;Ann Arbor, MI: Pluto Press.

Papastergiadis, Nikos. 2000. The Turbulence of Migration : Globalization, Deterritorialization, and Hybridity. Cambridge, UK; Malden, Mass.: Polity Press ; Blackwell Publishers.

Pezzani, Lorenzo, and Charles Heller. 2013. “A Disobedient Gaze: Strategic Interventions in the Knowledge(s) of Maritime Borders." Postcolonial Studies 16 (September): 289-98. https://doi.org/10.1080/13688790.2013.850047.

Sala, Antonio, Eduardo Durán, and Santiago López Petit. 2016. Crítica de La Izquierda Autoritaria En Cataluña, 1967-1974. 1. ed. Barcelona: Icara Editorial.

Scheel, Stephan. 2013a. "Autonomy of Migration Despite Its Securitisation? Facing the Terms and Conditions of Biometric Rebordering." Millennium 41 (3): 575-600. https://doi.org/10.1177/0305829813484186.

. 2013b. "Studying Embodied Encounters: Autonomy of Migration beyond Its Romanticization.” Postcolonial Studies 16 (3): 279-88. https://doi.org/10.1080/136 88790.2013.850046.

Shukaitis, Stevphen. 2012. "Below the Perceptible, the Political?" Rethinking Marxism 24 (3): 424-427.

Tazzioli, Martina. 2015. Spaces of Governmentality: Autonomous Migration and the Arab Uprisings. New Politics of Autonomy. London ; New York: Rowman \& Littlefield International.

Virno, Paolo. 2003. A Grammar of the Multitude: For an Analysis of Contemporary Forms of Life. Semiotext(e) Foreign Agents Series. Cambridge, Mass ; London: Semiotext (e).

Virno, Paolo, and Michael Hardt, eds. 2010. Radical Thought in Italy: A Potential Politics. Nachdr. Theory out of Bounds 7. Minneapolis, Minn.: Univ. of Minnesota Press.

Von Osten, Marion (2016) "New Borderlands: Work, Migration, Memes and Personal Geopolitics" in On Curating Journal, Issue 30, pp. 101-108.

Walters, William . 2015. "Migration, Vehicles, and Politics. Three Theses on Viapolitics" in European Journal of Social Theory 18: 4, pp. 469-488.

Walters Williams, and Barbara Lüthi. 2016. "The Politics of Cramped Space: Dilemmas of Action, Containment, and Mobility.'International Journal of Politics, Culture, and Society 29, no.4: pp. 359-66. 